\title{
SEIZURES IN CHÉDIAK-HIGASHI SYNDROME
}

\author{
CASE REPORT
}

\author{
GABRIEL R.DE FREITAS*, CLARISSA P.DE OLIVEIRA**, ROGÉRIO S. REIS***, \\ MARIA ROSA SARMENTO****, NEIDE K. GASPAR ${ }^{* * * * *,}$ \\ MARIANA FIALHO******, HERBERT PRAXEDES *******
}

\begin{abstract}
Chédiak-Higashi syndrome is a rare hematological disease characterized by increased fusion of cytoplasmatic granules. Neurological symptoms occur in approximately half of the patients. We describe the clinical, eletrophysiological, hematological and radiological findings in a girl who had Chédiak-Higashi syndrome and seizures.
\end{abstract}

KEY WORDS: Chédiak-Higashi syndrome, seizures, MRI.

\section{Crises convulsivas na síndrome de Chédiak-Higashi: relato de caso}

RESUMO - A síndrome de Chédiak-Higashi é uma doença hematológica rara caracterizada pelo aumento da fusão dos grânulos citoplasmáticos. Manifestações neurológicas ocorrem em cerca de metade dos pacientes. Relatamos o caso de uma criança com síndrome de Chédiak-Higashi e crises convulsivas.

PALAVRAS-CHAVE: síndrome de Chédiak-Higashi, epilepsia, ressonância nuclear magnética.

Chédiak-Higashi syndrome (CHS) is an autosomal recessive disease characterized by increased fusion of cytoplasmatic granules ${ }^{1}$. Beguez-Cesar, a Cuban pediatrician, reported the first three cases of CHS in 1943. Steinbrinck reported a single case in 1948, as did Higashi in 1954. Chédiak was the first to report the hematological abnormalities in 1952. In 1955, Sato coined the eponym ChédiakHigashi. Recently, the human CHS1 gene was mapped to chromosome 1q42-q4332,3. CHS has been described in most human populations. With the exception of a cluster of cases in the Venezuelan Andes, it is very rare. Patients exhibit partial oculocutaneous albinism, increased susceptibility to infections and the presence of giant granules in leukocytes. Most of the patients manifest partial albinism in at least one of three organs, the skin, the hair or the eyes. Neurological symptoms occur in approximately half of the patients ${ }^{4}$. Polyneuropathy is the most common manifestation, but cranial nerve palsies, mental retardation, cerebellar ataxia, parkinsonism, dementia and seizures have also been reported ${ }^{1,4-7}$. Diagnosis is made by demonstration of giant cytoplasmatic inclusions in granulocytes on a peripheral blood smear. There is no specific treatment of CHS, although bone marrow transplantation has shown satisfactory results ${ }^{1}$.

We describe a child presenting with seizures as neurological manifestation of CHS.

Hospital Universitário Antonio Pedro, Department of Neurology, Universidade Federal Fluminense : *Resident in Neurology; **Post Graduate Course in Neurology; ***Neurologist, ****Professor and Head of Epilepsy Division; *****Chairman of Dermatology Department; ******Resident in Dermatology; ********Chairman of Hematology Department. Aceite: 4-fevereiro-1999.

Dr. Gabriel Rodríguez de Freitas - Rua Gastão Ruch 16/1402 - 24220-100 Niterói RJ - Brasil. Email: gfreitas@nitnet.com.br 


\section{CASE REPORT}

An eleven-month-old white girl was evaluated for five episodes of generalized tonic-clonic seizures and one episode of tonic seizure. She had grayish hair and partial cutaneous albinism since four months of age (Fig 1). There was a history of recurrent pyogenic infections, especially skin infections, and upper and lower respiratory tract infections. Her development was otherwise normal. Neurological examination was normal, except for mild fotophobia. Ophthalmological evaluation did not disclose any abnormalities. Interictal EEG revealed recurrent symmetrical slow waves from 0.5 to $3 \mathrm{~Hz}, 70$ to $150 \mathrm{mV}$ and spike-and-wave discharges at a rate of 2.5-3 Hz. Cranial CT scan disclosed a small hypodense lesion in the right temporal subcortical area without contrast enhancement. MRI showed a cystic image in the right medial lobe, resembling CSF signal in T1, T2 and inversion recovery intensities. It was suggestive of a neuroephytelial cyst. Nerve motor and sensitive conduction studies were normal. Blood smear showed leukocytes with large granules (Fig 2). Seizures were successfully controlled with phenobarbital.

\section{DISCUSSION}

Seizures have long been noted as a neurological manifestation of $\mathrm{CHS}^{1,4-7}$. Both central and peripheral nervous system manifestations seem to be due to accumulation of lymphocytes and histiocytes in nervous tissue ${ }^{8,9}$.

There are few radiological studies of $\mathrm{CHS}^{6,7}$. They have showed marked diffuse brain atrophy, especially in the temporal lobe.

In our patient, the diagnosis of CHS was supported by partial albinism, abnormal susceptibility to infection and confirmed by the presence of giant granules in the leukocytes. The radiological studies were normal, except for the neuroephytelial cyst.

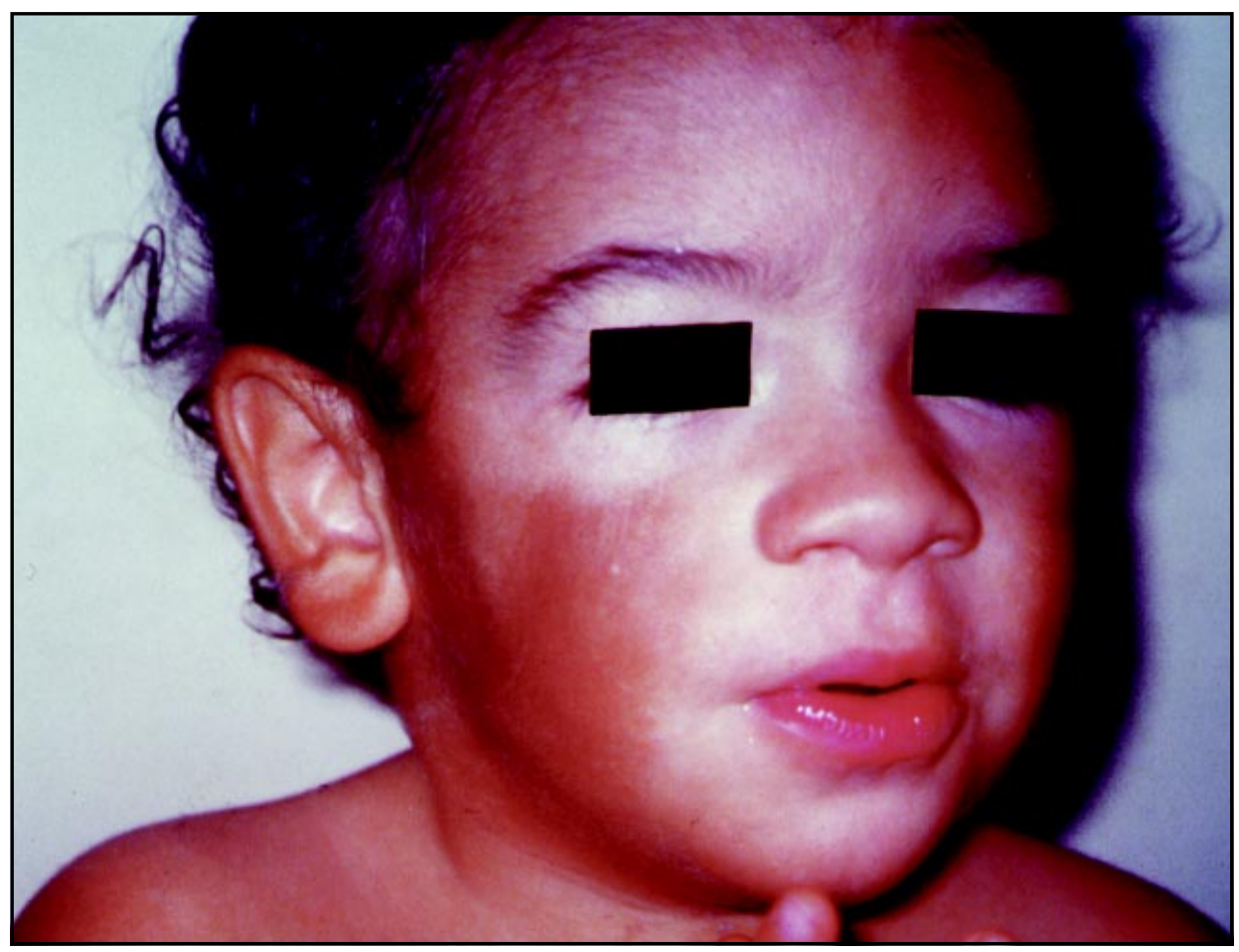

Fig 1. Features of Chédiak-Higashi syndrome: partial albinism and grayish hair. 


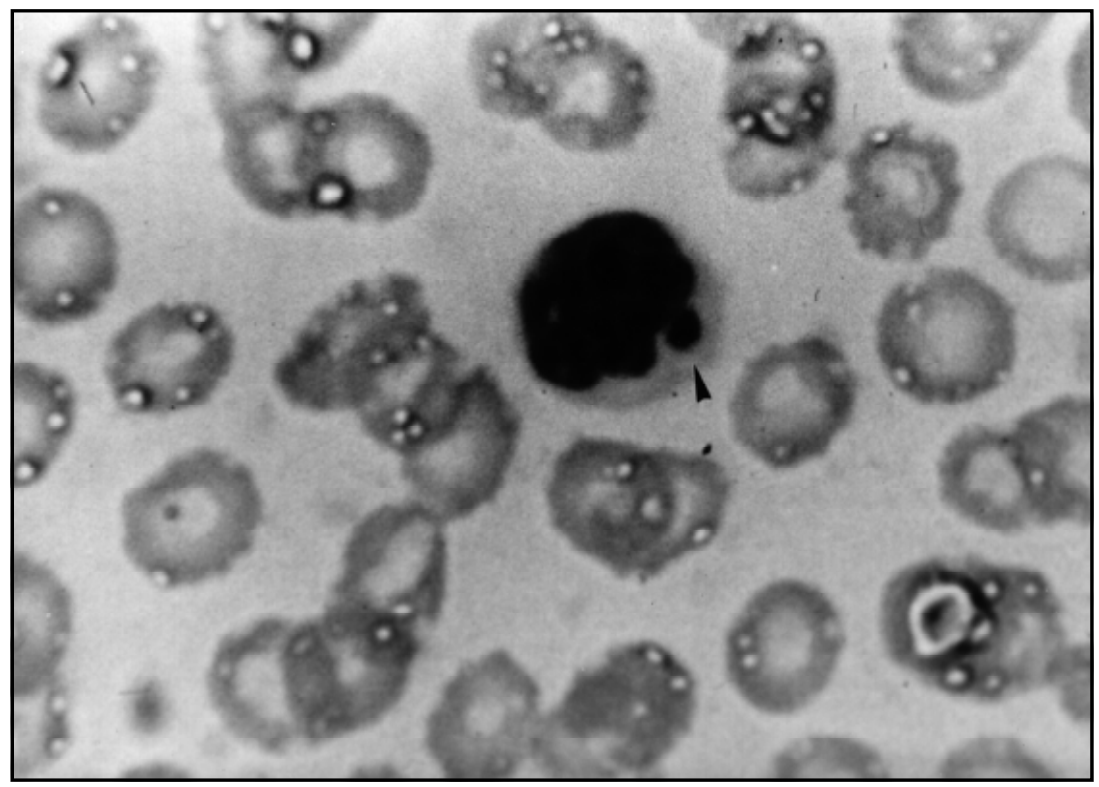

Fig 2. Giant cytoplasmatic inclusion (arrowhead) in a granulocyte on a peripheral blood smear.

We do not attribute seizures to the cyst. Problably they were complications of the disease. The other reports of seizures in CHS suggest that it is more than a matter of coincidence.

Although CHS is rare, its neurological manifestations are common and pleomorphic. As patients occasionally do not have oculocutaneous albinism neither increased susceptibility of infection, CHS needs to be differentiated from many primary neurological disorders. In some patients diagnosis is considered only after observation of giant intracellular granules as an incidental finding on a peripheral blood smear.

Acknowledgments - We are indebted to Dr. Jorge Moll Neto for the MRI realization and evaluation; to Dr. Peter Salem Junior for his review in English and to Dr. Tânia Escada and Maria Thereza Nevares for the nerve conduction studies.

\section{REFERENCES}

1. Spritz RA. Genetic defects in the Chediak-Higashi syndrome and the beige mouse. J Clin Immunol 1988;18:97-105.

2. Barrat FJ, Auloge L, Pastural E, et al. Genetic and physical mapping of the Chediak-Higashi syndrome on chromosome 1q42-q43. Am J Hum Genet 1996;59:625-633.

3. Fukai K, Oh J, Karim MA et al. Homozygosity mapping of the gene for Chediak-Higashi syndrome to chromosome 1q4244 in a segment of conserved syntety that includes the beige locus (bg). Am J Hum Genet 1996;59:620-624.

4. Adams RD, Victor M, Rooper AH. Principles of neurolorogy. 6. Ed. New York: McGraw-Hill, 1997:928-991.

5. Sheramata W, Kott HS, Cyr DP. The Chédiak-Higashi-Steinbrick syndrome: presentation of three cases with features resembling spinocerebelar degeneration. Arch Neurol 1971;25:289-294.

6. Uyama E, Hirano T, Ito K, et al. Adult Chédiak-Higashi syndrome presenting as parksonism and dementia. Acta Neurol Scand 1994;89:175-183.

7. Ballard R, Tien RD, Nohria V, Juel V. The Chédiak-Higashi syndrome: CT and MRI findings. Pediatr Radiol 1994;24:266267.

8. Lockman LA, Kennedy WR, White JG. The Chédiak-Higashi syndrome: electophysiological and electron microscopic observations on the peripheral neuropathy. J Pediatr 1967;70:942-951.

9. Page RA, Berendes H, Warner J, Good RA. The Chédiak-Higashi syndrome. Blood 1962;20:330-343. 